\title{
Communication Design and Space Narratives
}

\author{
Maria Luísa Costa and Inês Amaral
}

\begin{abstract}
The experience with space is achieved through projects developed according to a design perspective. In addition to collaborating on the creation of spatial narratives by promoting the experience, the design also acts in the sense of enhancing accessibility in both the physical and cognitive domain. Wayfinding systems as well as informational technological systems are informative elements that communicate with citizens, fostering experiences of greater accessibility and the creation of social space. This paper discusses the concept of space from its social dimension, questioning on how spatial narratives, places, and paths can create individual or collective experiences within urban space through Communication Design by the use of technology.
\end{abstract}

Keywords Communication design • Wayfinding systems • Spatial narratives • Georeferencing systems • Augmented reality

\section{Introduction}

The growth of cities manifests itself as a historical trend and particularly intense since the nineteenth century, due to the progressive conversion of the rural population into an urban population. Data published by the United Nations (UN) in 2008 prove the growth of cities and reflect the choices of individuals. A study by the Population Division of the UN Department of Social and Economic Affairs indicates that the

\author{
M. L. Costa $(\bowtie)$ \\ Centro de Investigação em Arquitetura, Urbanismo e Design, Universidade de Lisboa, Pólo \\ Universitário, Rua Sá Nogueira, Alto da Ajuda, 1349-063 Lisbon, Portugal \\ e-mail: design.luisacosta@gmail.com \\ Instituto Superior Miguel Torga, Largo da Cruz de Celas n 1, 3000-132 Coimbra, Portugal \\ I. Amaral \\ Faculdade de Letras da Universidade de Coimbra, Largo da Porta Férrea, \\ 3004-530 Coimbra, Portugal \\ Centro de Estudos de Comunicação e Sociedade, Universidade do Minho, Campus de Gualtar, \\ 4710-057 Braga, Portugal


world's population living in cities will double from 3300 million in 2007 to 6400 million in 2050. In 2008, for the first time in the history of Humanity, more than half the inhabitants of the planet lived in cities.

Combining the tendency of growth to the problematic of the hegemony of the city, it is confirmed the true protagonism that assumes the contemporary urban space and the necessity of an adequate communication that allows all the citizens to live and to experience the city in its fullness. The cities grew and evolved according to the citizens who inhabit it, as well as social and cultural needs of each era. These multi-layered structures prevail visible in each city, and it is possible to glimpse in these layers the stories and memories of the citizens who were successively inhabiting them, revealing and expressing the cities through this plurality and collective experiences. The public space of cities reflects their reality, their originality, the life and the character of the citizens, that is, what can differentiate it from the others, the reason why it is essential that the cities potentiate their public space, through a close connection, communicating and promoting access.

City and Design are keywords of contemporaneity with exponential growth from the Industrial Revolution. Cities are growing and increasingly influencing people's culture. Design becomes omnipresent in everyday life, and at each moment new needs and areas of intervention are identified for this disciplinary area. The importance of Communication Design in the city context manifests itself in the readability of the city itself, as well as in its communication and projection. The designer should act as a mediator facilitating the interaction and communication of the city and in the city. Contemporary discourses emphasize the role of design and its transformative action in the production of social consciousness.

Communication Design can intervene in space to provide experiences of fruition of this through wayfinding systems, which potentiate new experiences, mediation of social practices and the creation of places. If the function of wayfinding is orientation, its use leads to paths and the production of anthropological places (Augé 1994). However, the construction of spatial narratives and places through Communication Design can be increased with the use of technology. This chapter explores the concept of space from its social dimension and reflects on how spatial narratives, places, and paths create individual or collective experiences through Communication Design using technology.

\section{Social Dimension of Space}

The end of the project of colonialism and the beginning of the urban revolution has made it evident that it is not only a question of the built environment but of having a critical concept of space in order to understand its social dimension. Lefebvre (1995) claimed that there is only social space because there is no emptiness waiting to be filled. The author argued that it does not make sense to consider a preexisting space for social practices. Therefore, "the dichotomy space produced versus created space can be analyzed from power relations and their spatial echo" (Costa et al. 2019). 
Lefebvre's unit theory of space (Augé 1994) argued that the natural space is disappearing and societies produce their specific social space. Hence, reproductive, production and symbolic relations are evidenced in a triad of space: (i). Spatial practices: "The spatial practice of a society secretes that society's space; it propounds and presupposes it, in a dialectical interaction" (Lefebvre 1991); (ii). Representations of space: "Conceptualized space, the space of scientists, planners, urbanists, technocratic subdividers and social engineers, as of a certain type of artist with scientific bent - all of whom identify what is lived and what is perceived with what is conceived" (Lefebvre 1991); (iii). Representational spaces: "Space as directly lived through its associated images and symbols, and hence the space of 'inhabitants' and "users"" (Lefebvre 1991). The triad proposed by Lefebvre (1991) allows distinguishing produced space (reproducible space and that is a product) of created space (collective and continuous work).

The social space derives from social practices, symbolism, and reproductive and production relations (Lefebvre 1995). The daily social practices challenge the representational spaces, allowing sociological evolutions of spaces through constructed environments that derive from emergent forms of urbanity (de Certeau 1984). Therefore, social practices structure the determining conditions of social life. Consequently, the interpretation of space production stems from the circuit of discourses, practices, and social relations.

The relations of micro-power (Foucault 1984) that establish themselves in the social space construct spatial narratives that individualize places. Places and nonplaces are a dominant note of the contemporary social space (Augé 1994). Contemporary social and cultural practices unfold from the perspective of trends: a plethora of events and spaces and the individualization of references. The organization and constitution of places are modalities of collective and individual practices. Non-places are not symbolized and create a unique and non-relational identity, being empty of affectivity and, therefore, identified as spaces of passage (Augé 1994).

Augé approaches a reformulation of the notion of space and proposes an anthropology of 'over modernity', opening horizons beyond what the author considers to be a kind of 'ethnology of solitude' (Augé 1994). 'Over modernity' results from a world of excesses in terms of time, space and individualization. In the 'over modernity', circulation, communication and consumption prevail. This argumentation focuses on the premise of content and identity as elements both social and spatial. Therefore, contemporary social and cultural practices unfold in a perspective of trends: the superabundance of events and spaces and the individualization of references. In his theory, Augé (1994) differentiates space of place. The first has a more abstract and, therefore, more comprehensive definition: space is the notion of extension/distance between two points. The anthropological place generates identity, is associated with culture located in space and time, and reveals a construction with objectives and the relationships that individuals maintain with them. Augé's (1994) approach presupposes a multiplicity of spaces where places and non-places are distinguished, which take on the whole as contemporary spaces of circulation, communication and consumption. According to Augé (1994), the organization and constitution of places are modalities of collective and individual practices, for which the author states "the 
anthropological space is both a principle of meaning for those who inhabit it and a principle of intelligibility for those who observe it" (Augé 1994). Non-places are not symbolized and create a unique and non-relational identity, being empty of affective relationship and, therefore, identified as spaces of passage. In the traditional sense, a place is a space that can be occupied. Non-places correspond to spaces whose function is to enunciate potential routes to a given destination.

Lemos (2010) argues that "places are a result of negotiations among territories. Today, new senses of places emerge from these new layers of territories" (Lemos 2010). The author considers that "space is constituted by places that are created by inside territories in an endless process of mutual influences, horizontal and vertical (inside each category and among them). Today we have to take into account a new form of territory in contemporary societies: the digital, informational one. Every territory is a place of social control of borders, of informational exercise of surveillance and violence. The territoriality is a 'cultural artefact' that shapes social relations and our relationship with the material and symbolic world. We are always immersed in territorial layers (subjectivity, physical, cultural, political, economic), and these layers constitute places" (Lemos 2010).

Lemos's perspective does not focus on the idea of the end of places or non-places (Augé 1994), but rather on the creation of "new senses of places, territories, mobility, and community" (Lemos 2010). It follows that the spaces are created by territorial dynamics and, accordingly, are "production of social meaning (emotional, historical, cultural, political, imaginary)" (Lemos 2010). It is on the basis of this assumption that the author argued: "space is a vacuum, place is produced" (Lemos 2010).

The emergent forms of urbanity that are produced and reproduced by design projects in the built environment are elements of communication that foster networks of significance and meaning sketched by subjects who draw their own subjectivity. The way each citizen relates to the city is different. The dynamics of contemporaneity, mobility and mutation are processes that will build citizenship, in micro and macro scales, in a discourse in which "I" and "Other" are a continuum in alternation. The city can be interpreted as a portrait of mental and symbolic maps that reflect a different way of appropriating the same space depending on the presence of individuals and the relationships between them (Costa and Amaral 2018). Public space, rather than the emptiness between buildings, is the place where the citizen feels and lives the city in what is most genuine (Costa et al. 2019). The public space is the place of construction of multiple memories and spatial narratives grounded in experiences both individual and collective (Costa and Amaral 2018).

\section{Connecting People to Space}

Wayfinding systems are informative elements that communicate with citizens, fostering experiences of greater accessibility in the public space. Mollerup (2005) considers that wayfinding systems intended for 'wayfinders', which it defines as being people walking or cycling, and whose objective is to find a specific place. The function 
of wayfinding systems is to enable people to complete their journeys successfully. According to the author (Mollerup 2005), finding and showing the way are activities as old as Humanity itself, asserting wayfinding systems as a means to solve a problem.

This ancestral need is inscribed in our symbolic and oneiric universe. Examples are manifested from Greek mythology where Ariadne, through the wire delivering Theseus, finds the possibility of this finding the way out of the maze; or in children's stories such as of the brothers Grimm "Hansel and Gretel", and in which Hansel marks the way to be able to return home.

The study of wayfinding systems, and the areas directly related to them such as typographic readability, color perception, systems for the blind, among others promoted the development of cognitive sciences (Berger 2009). It is common to confuse signage with wayfinding. Signage is effectively part of a wayfinding system, but this covers many more areas, such as architecture, landscaping, lighting, signage and information systems being only part of the wayfinding. Over time, wayfinding systems have undergone significant changes due to social and cultural needs, which are interconnected with the means available and technological evolution. The need to show and make accessible paths has increased, with wayfinding systems essential in the face of population growth, urban growth and the need to access increasingly complex spaces.

Lynch (1960) uses for the first time the term 'wayfinding' in his book the "Image of the City" and relates to the process of forming a mental picture of one's surroundings based on sensation and memory. It is also in this perspective that Passini (1996) states that the wayfinding concept integrates the notion of spatial orientation, which means the psycho-ability of a person to mentally represent the spatial characteristics of a given environment and to stand within that representation.

Thus, the wayfinding consists of a comprehensive concept that incorporates the notion of spatial representations, being "composed of three interrelated processes: (1) decision making and the development of decision plans also called action plans: (2) decision execution, transforming decision plans into behavior at the right time and place along a route: and (3) information processing, comprising environmental perception and cognition which provide the person with the information necessary for the two decision-related processes" (Passini 1996).

The need for in-depth study of wayfinding systems led in the 1970s to the creation of the Society of Environmental Graphic Design (Gibson 2009). The name of this association has been changing over the years reflecting the changing paradigms of society. Today, in a society where experience is prioritized, the association is called the Society for Experiential Graphic Design, self-describing itself as a community that connects people and places by way of planning, designing and building experiences.

The wayfinding is a set of processes and methods that enable information to physical movement of a point to another and wherein like elements architecture, the surrounding space, the lighting art and technology assume leading roles. According to Berger (2009), it consists of a set of activities that allow us to find the way to a certain destination. Passini (1996) states "wayfinding design concerns all features 
of the built environment which are related to the purposeful circulation of people and their ability to mentally situate themselves in a setting. These design features include spatial layouts, architectural features related to circulation and graphic displays including audible and tactile supports". Rosa (2012) considers that wayfinding systems allow the user to easily find their destination through the creation or use of multiple visual, physical and sensorial resources. This connection to physical and sensorial resources refers to the idea of experience and to the importance that it assumes in contemporaneity.

These definitions echo the aforementioned Society for Experiential Graphic Design, whose objectives are to create experiences that connect people with the place, creating environments that improve the experience and make them more dynamic, through technologies. Berger (2009) points out that future difficulties in the field of space graphic design are difficult to predict, and it is almost guaranteed that designers will need to embrace in their projects an even broader and improved set of transversal capabilities where new spaces will be feasible through the blending of virtual reality, cyberspace, and multiple intelligent materials.

The main means used in wayfinding systems usually consist of maps and signal systems, symbols and colors that indicate the direction of individuals. Progressively these means integrate mobile applications and automatic identification systems, paving the way for new approaches in wayfinding systems, namely the use of systems of georeferencing and Augmented Reality (AR). Amaral (2012) states that digital is not disconnected from the so-called offline world. It will be rather an intermediate space with presence simulations, through the realization of belonging in digital environments and the development of new sociabilities without territory.

\section{Technology and (New) Space Narratives}

The rehabilitation of urban spaces has been one of the focus of design, making it a responsible part of the creation of built environments that enhance political, environmental, social, cultural and economic awareness. Communicating the city, with its idiosyncrasies, is an integral part of the professional practice of design. Therefore, the answer has been the development of information systems that allow the spatial organizational fluidity and experiences of space enjoyment. Through the systems of georeferencing and augmented reality, technology enables a reformulation of social spaces and the creation of places of individual or collective experiences.

The influence of new technologies in public and private spheres of society has given rise to a new social field and directly interferes with how citizens perceive and relate to the city. In Bourdieu's (2001) theory, field arises as a configuration of socially distributed relations. According to the author, the field represents a symbolic space in which mediation between social agents and society takes place. In this perspective, the social field is a system of positions, which can be challenged and altered. It follows that the fields are microcosms with their laws. Therefore, agent strategies are determined by capital (cultural, social, economic, political) and the habitus (schemes 
of perception, thought and action) of individuals. In this chapter, we adopt the concept of the social field proposed by Bourdieu (2001), which refers us to symbolic social spaces that follow from paths proposed by technological systems. These itineraries also anchor in perceptions, identities and memories that compete for representations of the social world through interaction with digital systems of spatial representation.

In digital spaces, the social dimension of shared construction of meanings and representations replaces the physical place. The idea of territory is diluted in simulacra of presence, feelings of belonging, permanence and own codes. Since the Internet and digital spaces are eminently symbolic spaces, information and the context of interaction are assumed as preponderant elements in the process of reformulation of spatiotemporal notions (Gomes 2000) and spatial representations. Therefore, the transformation of spaces into anthropological places results from processes of individual and social cognition within the dynamics of the new forms of sociability that result from the introduction of interactive technology in individual and collective spatial narratives. It is therefore essential to understand that the scenario of the new generation of digital devices in which the user is effectively proactive, using tools that allow content sharing, worldwide dissemination and the association of users in the context of networks of interests changes the perception of the user and encourages the merger of this with the consumer (Amaral 2012).

The concepts of 'user-generated content' and 'user-generated media' make it possible to maximize the notion of participation on the Internet through the formation of social networks of contents that are in permanent mutation, where social representations are decontextualized, disaggregated and consumed collectively (Amaral 2012, 2016). In the context of this type of structures, semantics is essential for the understanding of the development of new practices and, consequently, relationships based on streaming of contents, drawn by appropriations of the technique. As Jones postulated, "Computer-mediated communication, it seems, will do by way of electronic pathways what cement roads were unable to, namely, connect us rather than atomize us, put us at the controls of a 'vehicle' and yet not detach us from the rest of the world" (Jones 1997).

The technique, through the tools of communication, creates mechanisms of interaction that, by themselves, are assumed as spaces of collective narratives and shared social representations through georeferencing systems and content indexation through geotagging (Amaral 2016). The purposes of using semantic indexing are varied. These practices refer to the formation of networks where information circulates, and social connections are established. In our perspective, and adopting the argument of Barata (1989), sociability is the result of all the interactions that occur in the social field. In this sense, it concerns the form of social relations and summarizes phenomena of interaction or the ability to found groups and build networks supported in the ties between individuals (Ferréol 2007). Therefore, semantic indexing in systems of georeferentiation can be concretized in spontaneous and organized sociability (Gurvitch 1986).

Georeferencing systems use geolocation applications that allow personalized local search experience (Amaral 2014). Through a global positioning system (GPS), it is possible to access interactive wayfinding systems or location-based social media 
services applications. Foursquare and Swarm are two examples of location-based social media service application. Facebook or Twitter, as social networking tools, also allow georeferencing. These applications use "global positioning-system (GPS) in mobile devices to generated locations and provides the list of places. 'Check-in' is the process of identifying the location where the user is" (Amaral 2014).

Geotagging can be defined as "the process of adding metadata with geographical identification to content. It is also defined as a form of geospatial metadata" (Amaral 2015). Geotagging allows spatial indexing of content as it is a process of recognized geographic locations which enhances the development of geographic databases, Web resources, as well as multimedia content. This practice changes how the user interacts with content and other users in the digital space. Applications and systems with geotagging capabilities often add latitude and longitude coordinates, distance, and place names to media content. The added data consist of textual and visual resources (Amaral 2015).

As a communicational practice, wayfinding systems depend on sociocultural needs and technologies. The use of maps becomes obsolete, and we hardly imagine individuals moving by car, guided by a map in paper form, as well as with whom one moves on foot. GPS systems have revolutionized the way we project into space and move into space. Thus, maps have fallen into disuse making their reading and interpretation increasingly difficult. This situation happens both with young people who favor the use of technologies and by other age groups where lack of acuity makes it impossible to read these maps.

The increasing ease with which individuals interact with mobile devices, the enhancement of their capabilities, as well as all the resources available online, open possibilities in the context of the creation of differentiated products for use in wayfinding systems, emphasizing the Augmented Reality (AR).

AR provides interactive experiences that are so valued today in our society. AR creates layers that overlap the 'real' world, allowing access to differentiated information, more in-depth or more playful, depending on the goal to be achieved. The addition of a layer of virtual information in the physical context can significantly alter the way we understand the wayfinding systems and access to different information. Many companies, such as Google, are already exploring this possibility. In addition to finding a way, individuals can experience and experience spaces through expositive content, immersive experiences using analogical media and multimedia installations.

Although entirely different, concepts such as Augmented Reality (AR) and Virtual Reality (VR), are somewhat connected, and there is some confusion among its functionalities, which it is essential to clarify. VR creates a virtual and interactive world, through which it can include the senses of sight, hearing, and touch. AR also provides interactive experiences; however aims to be a supplement to the real world rather than creating an artificial environment (Höllerer and Feiner 2004).

The use of AR in wayfinding systems consists of the provision of additional and punctual information and can be used in reading paper maps to be used both in outer and inner space, but without the need for a full immersion as will be necessary 
in games or other immersive activities, the technology of which may prove to be tiresome and damage to the health of users.

Azuma (1995, 1997) considers that the designation Virtual Environments is more adequate than Virtual Reality, because it allows a more precise description of the effects achieved. However, whether one term or another term is used, the difference between VR and AR is in their treatment of the real world. Virtual Environments completely replace the real world with a computer-generated synthetic environment that completely immerse the user inside this environment Azuma (1997). In turn, Augmented Reality adds virtual information to the 'real' world through user insight and never replaces it. It follows allowing an intersection of the 'real' and virtual worlds (Azuma 2017).

Azuma (2017) states that AR will succeed in the consumer market sooner if it can establish new forms of media that users find compelling. Considering that AR will make it possible to establish meaningful connections between the surrounding real environment and virtual contents, generating experiences whose value results precisely from this connection and not just from one of the worlds.

\section{Conclusions}

Georeferencing systems and augmented reality are intelligent and interactive systems that allow users to interact with space through technological interfaces. These systems individualize spatial experiences, foster new modalities of practices in space, and recreate symbolic representations. The construction of individual or collective paths within space allows the creation of new spatial narratives amplified by technology and communication systems.

Identity, memory, and individual and collective experiences contribute to the construction of spatial narratives through digital devices. These narratives can be individual or collective and often become public and therefore shared through social media. The same itinerary, which previously focused on individualistic logic, can now be experienced through a collective narrative to which different people contribute through the recording of their perception of space, materialized in data and metadata. Hence, different forms of sociability arise that allow the construction of collective narratives in which social bonds are established.

Individual narratives that enhance immersion and unique experiences enable the construction of spatial representations that result from a mix between the perception of the moment and the memories that give meaning to the symbols.

The issue of references and formatting of thought have been questionable elements in the production of space in contemporary times. Urban design has even come to be seen as a break with the past, enhancing emerging landscapes. Are we faced with the emergence of abstract spaces, which enable representations and imaginations of space in a reconfiguration of the relations of power and their materialization in space practices? 
We conclude that emerging forms of urbanity created by urban design for sustainability, based on the question of "glocalization", point to a perspective of new structures of sociability that result from a spatialization endowed with multiple identities and memories. We assume as a premise Benjamin's (2001) argument about urban itineraries and collective memory to compete for new forms of sociability in the contemporary urban world.

\section{References}

Amaral I (2012) Participação em rede: do utilizador ao "consumidor 2.0" e ao "prosumer" [Network participation: from the user to the "consumer 2.0" and the "prosumer"]. Revista Comunicação e Sociedade 22, 131-147

Amaral I (2014) Geotaging. In: Harvey K (ed) Encyclopedia of social media and politics, vol. 2. Sage Publications, Thousands Oaks, pp 574-575 (2014)

Amaral I (2015) Foursquare. In: Wherry FF, Golson JG (eds) The Sage encyclopedia of economics and society, vol 2. Sage Publications, Thousands Oaks, pp 727-728

Amaral I (2016) Redes Sociais: sociabilidades emergentes [Social Networks: emerging sociabilities]. Editora LabCom.IFP, Covilhã

Augé M (1994) Não-Lugares: Introdução a uma Antropologia da Sobremodernidade [NonLocations: Introduction to an Anthropology of Overmodernity]. Bertrand Editora, Lisboa

Azuma R (1995) Predictive tracking for augmented reality. Ph.D. dissertation, University of North Carolina at Chapel Hill, Department of Computer Science

Azuma R (1997) A survey of augmented reality. Presence Teleoperators Virtual Environ 6(4):355385

Azuma R (2017) Making augmented reality a reality. In: Proceedings of OSA Imaging and Applied Optics Congress (2017)

Barata O (1989) Introdução às Ciências Sociais [Introduction to Social Sciences]. Bertrand Editora, Venda Nova

Benjamin W (2001) Sociologia [Sociology]. São Paulo, Ática

Berger C (2009) Wayfinding: designing and implementing graphic navigational systems. Rockport Publishers

Bourdieu P (2001) O poder simbólico [The symbolic power]. Difer, Lisboa

Costa ML, Amaral I (2018) Cidades e Sistemas Wayfinding. Convergências - Revista de Investigação e Ensino das Artes XI(21) (2018)

Costa ML, Amaral I, Daniel F (2019) The contribution of information design to age-friendly cities: s case study on Coimbra and public transport. In: Rebelo F, Soares MM (eds) AHFE 2018, AISC 777. Springer International Publishing AG, Berlin, pp. 485-496

de Certeau M (1984) The practice of everyday life. University of California Press, Berkeley

Ferréol G (2007) Sociologia: Léxico das Ciências Sociais [Sociology: Social Sciences Lexicon]. Porto Editora, Porto

Foucault M (1984) Space, knowledge and power. Foucault Reader 239(256)

Gibson D (2009) The wayfinding handbook: information design for public places. Princeton Architectural Press, Princeton

Gomes C (2000) Novos mapas culturais e o ciberespaço [New cultural maps and cyberspace]. Passados Recentes, Futuros Próximos, Universidade de Coimbra, Actas do IV Congresso Português de Sociologia - Sociedade Portuguesa(2000)

Gurvitch G (1986) A vocação actual da Sociologia [The current vocation of Sociology]. Cosmos, Lisboa 
Höllerer T, Feiner S (2004) Mobile augmented reality. In: Karimi H, Hammad A (eds) Telegeoinformatics: location-based computing and services. Taylor and Francis Books, Boca Raton, pp 221-260(2004)

Jones S (1997) Virtual culture. Identity \& communication in cybersociety. Sage Publications, Thousand Oaks

Lefebvre H (1991) The production of space. Blackwell Publishing, Oxford

Lefebvre H (1995) The right to the city. In: Lefebvre H, Kofman E, Lebas E (eds) Writings on cities. Blackwell, Cambridge, pp 63-184

Lemos A (2010) Post - mass media functions, locative media, and informational territories: new ways of thinking about territory, place, and mobility in contemporary society. Space Culture 13(4):403-420

Lynch K (1960) A Imagem da Cidade [The Image of the City]. Edições 70, Lisboa

Mollerup P (2005) Wayshowing: a guide to environmental signage. Lars Muller Publishers

Passini R (1996) Wayfinding design: logic, application and some thoughts on universality. Des Stud 17(3):319-331

Rosa C (2012) Informação Pictográfica - O universo dos pictogramas: Métodos e procedimentos de design para obtenção de coerência formal [Pictographic Information - The universe of pictograms: Design methods and procedures for obtaining formal coherence]. Ph.D. thesis, Faculdade de Arquitectura da Universidade Técnica de Lisboa (2012) 